\title{
Development of Sensitive Droplet Digital PCR Assays for Detecting Urinary TERT Promoter Mutations as Non-Invasive Biomarkers for Detection of Urothelial Cancer
}

\author{
Md Ismail Hosen ${ }^{1,2}{ }^{\oplus}$, Nathalie Forey ${ }^{1}$, Geoffroy Durand ${ }^{1}$, Catherine Voegele ${ }^{1}$, Selin Bilici ${ }^{1}$, \\ Patrice Hodonou Avogbe ${ }^{1}$, Tiffany Myriam Delhomme 1ํ, Matthieu Foll ${ }^{1}{ }^{1}$, Arnaud Manel ${ }^{3}$, \\ Emmanuel Vian ${ }^{4}{ }^{\mathbb{D}}$, Sonia Meziani ${ }^{1}$, Berengere De Tilly ${ }^{4}$, Gilles Polo ${ }^{4}$, Olesia Lole ${ }^{1}$, \\ Pauline Francois ${ }^{1}$, Antoine Boureille ${ }^{1}$, Eduard Pisarev $\left.{ }^{5}{ }^{(}\right)$, Andrei R. O. S. E. Salas ${ }^{1,6}{ }^{\oplus}$, \\ Sara Monteiro-Reis ${ }^{7}{ }^{\mathbb{D}}$, Rui Henrique ${ }^{7,8,9}{ }^{\mathbb{D}}$, Graham Byrnes ${ }^{1}$, Carmen Jeronimo ${ }^{7,8,9}{ }^{(D)}$, \\ Ghislaine Scelo ${ }^{1,10}$, James D. McKay ${ }^{1}$, Florence Le Calvez-Kelm ${ }^{1, *}$ (D) and Maria Zvereva ${ }^{1,11, *(D)}$ \\ 1 International Agency for Research on Cancer (IARC), 69372 Lyon, France; ismail.hosen@du.ac.bd (M.I.H.); \\ ForeyN@iarc.fr (N.F.); geoffroy.durand@med.lu.se (G.D.); VoegeleC@iarc.fr (C.V.); \\ biliciselin10@gmail.com (S.B.); patrice.avogbe@fast.uac.bj (P.H.A.); \\ tiffany.delhomme@irbbarcelona.org (T.M.D.); FollM@iarc.fr (M.F.); sonia.meziani8@gmail.com (S.M.); \\ olesia.lole@gmail.com (O.L.); pauline.francois@i2bc.paris-saclay.fr (P.F.); antoine.boureille@gmail.com (A.B.); \\ andrei.escartinsalas@gmail.com (A.R.O.S.E.S.); ByrnesG@iarc.fr (G.B.); ghislaine.scelo@gmail.com (G.S.); \\ MckayJ@iarc.fr (J.D.M.) \\ 2 Department of Biochemistry and Molecular Biology, Faculty of Biological Sciences, University of Dhaka, \\ Dhaka 1000, Bangladesh \\ 3 Le Creusot Hospital, 71200 Le Creusot, France; ArMANEL@hoteldieu-creusot.fr \\ 4 Department of Urology, Protestant Clinic of Lyon, 69300 Caluire-et-Cuire, France; \\ emmanuel.vian@infirmerie-protestante.com (E.V.); berengeredetilly@hotmail.com (B.D.T.); \\ gilles.polo@infirmerie-protestante.com (G.P.) \\ 5 Faculty of Bioengineering and Bioinformatics, Lomonosov Moscow State University, 119234 Moscow, Russia; \\ e.pisarev@fbb.msu.ru \\ 6 Santa Casa de Sao Paulo School of Medical Sciences, Sao Paulo 01221-020, Brazil \\ 7 Portuguese Oncology Institute of Porto, Research Center (CI-IPOP), 4200-072 Porto, Portugal; \\ sara.raquel.reis@ipoporto.min-saude.pt (S.M.-R.); henrique@ipoporto.min-saude.pt (R.H.); \\ carmenjeronimo@ipoporto.min-saude.pt (C.J.) \\ 8 Department of Pathology, Portuguese Oncology Institute of Porto (IPOP), 4200-072 Porto, Portugal \\ 9 Institute of Biomedical Sciences Abel Salazar, University of Porto (ICBAS-UP), 4099-002 Porto, Portugal \\ 10 Department of Medical Sciences, University of Turin, 8-10124 Turin, Italy \\ 11 Department of Chemistry, Lomonosov Moscow State University, 119991 Moscow, Russia \\ * Correspondence: lecalvezf@iarc.fr (F.L.C.-K.); mzvereva@chem.msu.ru (M.Z.); Tel.: +7-49-5939-4533 (M.Z.)
}

Received: 23 October 2020; Accepted: 23 November 2020; Published: 27 November 2020

Simple Summary: The gold standard method for the diagnosis of bladder cancer (BC) is the invasive and expensive cystoscopy. Telomerase reverse transcriptase (TERT) promoter mutations occur frequently (60-90\%) in BC. In this study, we developed highly sensitive droplet digital PCR (ddPCR) assays for detecting low-allelic fraction TERT promoter mutations (C228T, C228A, CC242-243TT and C250T) in urinary cell-free and/or cell pellet DNA of BC patients and compared their performance with our previously established NGS-based assay (UroMuTERT) in two independent case-control studies: DIAGURO ( $n=89$ cases and $n=92$ controls) and IPO-PORTO ( $n=49$ cases and $n=50$ controls). The sensitivity and specificity of the ddPCR assays in detecting TERT promoter mutations in BC cases and controls were very high and comparable to the UroMuTERT assay. However, the technical and analytical simplicity of the ddPCR assays make them suitable candidates for clinical implementation. 
Abstract: Somatic mutations in the telomerase reverse transcriptase (TERT) promoter regions are frequent events in urothelial cancer (UC) and their detection in urine (supernatant cell-free DNA or DNA from exfoliated cells) could serve as putative non-invasive biomarkers for UC detection and monitoring. However, detecting these tumor-borne mutations in urine requires highly sensitive methods, capable of measuring low-level mutations. In this study, we developed sensitive droplet digital PCR (ddPCR) assays for detecting TERT promoter mutations (C228T, C228A, CC242-243TT, and C250T). We tested the C228T and C250T ddPCR assays on all samples with sufficient quantity of urinary DNA (urine supernatant cell-free DNA (US cfDNA) or urine pellet cellular DNA (UP cellDNA)) from the DIAGURO ( $n=89 / 93$ cases and $n=92 / 94$ controls $)$ and from the IPO-PORTO ( $n=49 / 50$ cases and $n=50 / 50$ controls) series that were previously screened with the UroMuTERT assay and compared the performance of the two approaches. In the DIAGURO series, the sensitivity and specificity of the ddPCR assays for detecting UC using either US cfDNA or UP cellDNA were $86.8 \%$ and $92.4 \%$. The sensitivity was slightly higher than that of the UroMuTERT assay in the IPO-PORTO series (67.4\% vs. $65.3 \%$, respectively), but not in the DIAGURO series (86.8\% vs. $90.7 \%)$. The specificity was $100 \%$ in the IPO-PORTO controls for both the UroMuTERT and ddPCR assays, whereas in the DIAGURO series, the specificity dropped for ddPCR (92.4\% versus 95.6\%). Overall, an almost perfect agreement between the two methods was observed for both US cfDNA $(n=164$; kappa coefficient of 0.91$)$ and UP cellDNA ( $n=280$; kappa coefficient of 0.94$)$. In a large independent series of serial urine samples from DIAGURO follow-up BC cases $(n=394)$, the agreement between ddPCR and UroMuTERT was (i) strong (kappa coefficient of 0.87), regardless of urine DNA types (kappa coefficient 0.89 for US cfDNA and 0.85 for UP cellDNA), (ii) the highest for samples with mutant allelic fractions (MAFs) $>2 \%$ (kappa coefficient of 0.99 ) and (iii) only minimal for the samples with the lowest MAFs ( $<0.5 \%$; kappa coefficient 0.32 ). Altogether, our results indicate that the two methods (ddPCR and UroMuTERT) for detecting urinary TERT promoter mutations are comparable and that the discrepancies relate to the detection of low-allelic fraction mutations. The simplicity of the ddPCR assays makes them suitable for implementation in clinical settings.

Keywords: droplet digital PCR; liquid biopsy; bladder cancer; TERT promoter mutations; urinary biomarkers

\section{Introduction}

Bladder cancer (BC), accounting for $90 \%$ of urothelial cancer (UC), is the 10th most common cancer worldwide [1]. There are two major groups of BC patients with distinctive clinical outcome and molecular features: Non-muscle-invasive and muscle-invasive [2]. Owing to the high recurrence rate of the non-muscle-invasive BC and expensive cystoscopy as a gold-standard diagnostic method, BC is one of the most expensive cancer to treat and manage [3]. The current guidelines for routine diagnosis and monitoring of $\mathrm{BC}$ rely on a sensitive but invasive cystoscopy as the gold standard and urine cytology, which is relatively less sensitive than cystoscopy, especially for low-grade non-muscle-invasive BC [4]. The invasiveness, risk of complications, and high expense of the cystoscopy technique poses significant challenges to the management of $\mathrm{BC}$, especially in subjects at sufficiently low-risk for BC, for whom invasive testing may be replaced by highly sensitive and specific methods for non-invasive detection of BC. Currently, clinical guidelines for the follow-up of patients with asymptomatic microscopic hematuria $(\mathrm{AMH})$ recommend invasive cystoscopy testing, with only a small fraction of $\mathrm{AMH}$ patients developing bladder cancer [5]. Individuals exposed to BC carcinogens at their workplace and therefore under regular medical surveillance may also benefit from a BC screening strategy using urine biomarkers with higher diagnostic predictive values than the common non-invasive tests (hematuria and urine cytology). Urine-based biomarkers may therefore be useful in these clinical scenarios, thereby contributing to early detection of BC and subsequent monitoring [6]. However, 
to date, no reliable non-invasive biomarker has been proposed for routine $\mathrm{BC}$ clinical management or for screening populations at risk of $\mathrm{BC}$. Therefore, detecting molecular alterations of the bladder tumor in the urine promises to be an important addition in the liquid biopsy of $B C[7,8]$.

Two mutations in the promoter of the Telomerase reverse transcriptase gene (TERT), called C228T and C250T, are frequent in various human cancers and particularly in UCs (carcinomas of the bladder and upper urinary tract) where it is seen in $60-85 \%$ of cases ( $74 \%$ for non-invasive UCs) $[9,10]$. Should these mutations be detectable in the urine of $\mathrm{BC}$ patients as a means of liquid biopsy, they would provide an unprecedented opportunity for a simple diagnostic assay of UCs, which could be used for detection as well as monitoring progression and recurrence. We have recently developed a Next-Generation Sequencing (NGS)-based assay, called UroMuTERT, for the comprehensive detection of BC in urine cell pellet and cell-free DNA samples [11]. We specifically showed in case-control studies that urinary TERT promoter mutations have excellent sensitivity and specificity for the detection of BC [11] and that these mutations could also be detected in urinary DNA of asymptomatic individuals years prior to primary diagnosis of $\mathrm{BC}$ with high specificity [12], highlighting their potential to be used as simple and inexpensive non-invasive biomarkers for early detection of BC. While the NGS assay shows great promise in detecting TERT promoter mutations in urine samples, the complex laboratory workflow and requirement of extensive bioinformatics skills for data analysis are still considered as a bottleneck for their large-scale clinical application.

In this study, we report the development of sensitive droplet digital PCR assays for detecting TERT promoter mutations in urine samples. We also present for the first time the comparison of ddPCR- and NGS-based assays for the detection of TERT promoter mutations in urine samples from a series of $\mathrm{BC}$ patients and controls.

\section{Results}

\subsection{Optimization of the ddPCR Assays}

The GC content of the TERT promoter region is approximately $80 \%$ which causes the formation of G-quadruplex structures [13,14]. The two most common somatic mutations of the TERT promoter (C228T and C250T) occur within the terminal G-tracts of the second putative quadruplex sequence [14]. These higher-level organization at the TERT promoter mutation sites poses a significant threat for the ddPCR assays to show distinct droplet clusters. To resolve this issue, we used 7-deaza-dGTP, Li-salt at a $2 \mu \mathrm{M}$ concentration. We optimized the concentration of 7-deaza-dGTP by a series of experiments with or without 7-deaza-dGTP in the PCR reactions (data not shown) and found that the addition of $2 \mu \mathrm{M}$ 7-deaza-dGTP resulted in a clear separation of droplet clusters (Figure 1). The effect of 7-deaza-dGTP in improving the ddPCR cluster resolution is in concordance with the results obtained by Colebatch et al. [15]. 

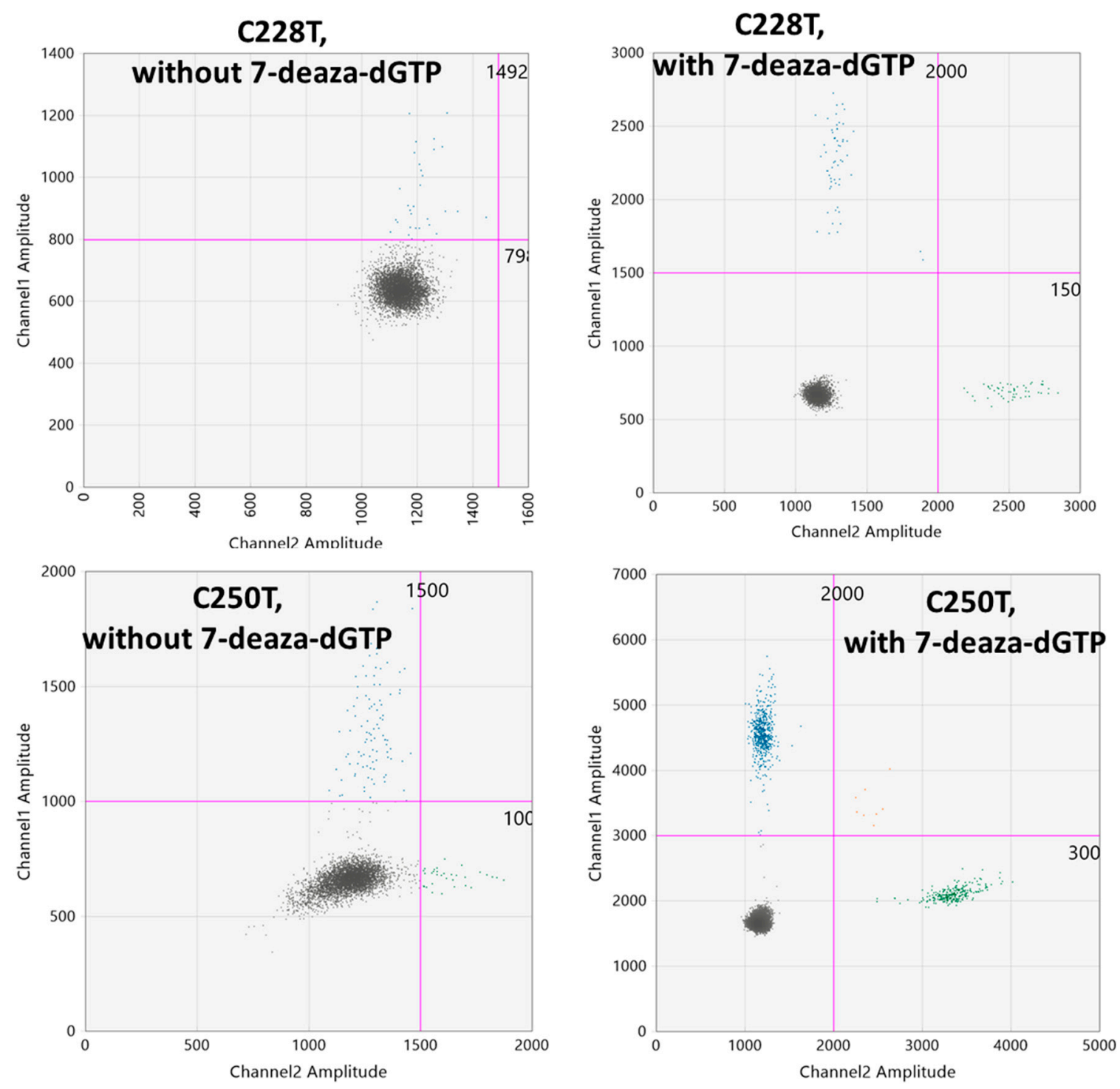

Figure 1. Effect of the 7-deaza-dGTP reagent $(2 \mu \mathrm{M})$ in generating clear droplet clusters for C228T and C250T assays.

\subsection{Determination of the Threshold Number of Minimum Mutated Droplets to Call a Mutation}

In order to determine the false positive measures and consequently the threshold number of minimum mutated droplets detected in the channel with the mutated probe, 20 DNA samples wildtype for the respective TERT mutations were assayed using the respective ddPCR assays. We used the Poisson regression results generated for wild-type samples (Figure 2) to determine the level of unspecific fluorescence for each of the ddPCR assays and infer for each assay the minimum of positive droplets to consider a sample as harboring the mutation. A minimum number of 5 or 6 positive droplets (mutated blue droplets above the Channel 1 thresholds) were considered to be positive in ddPCR for C228A/C250T and C228T/CC242-243TT assays, respectively. 
A. Poisson regression of TERT C228T - WT cell lines

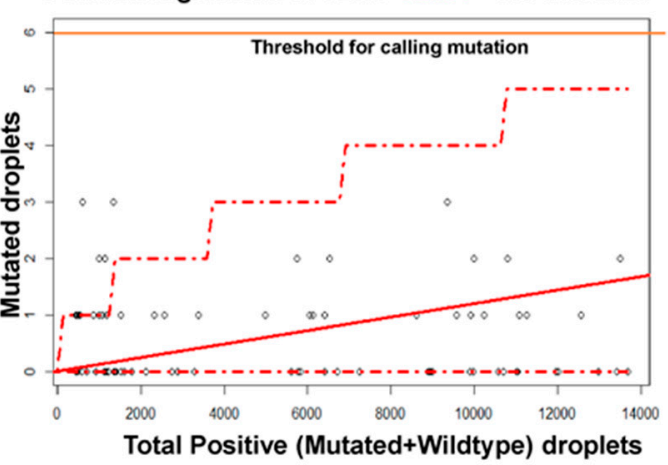

C. Poisson regression of TERT C228A - WT cell lines

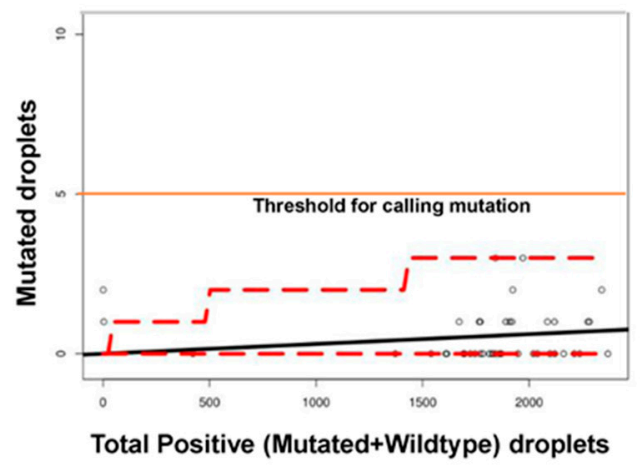

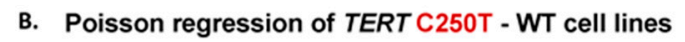

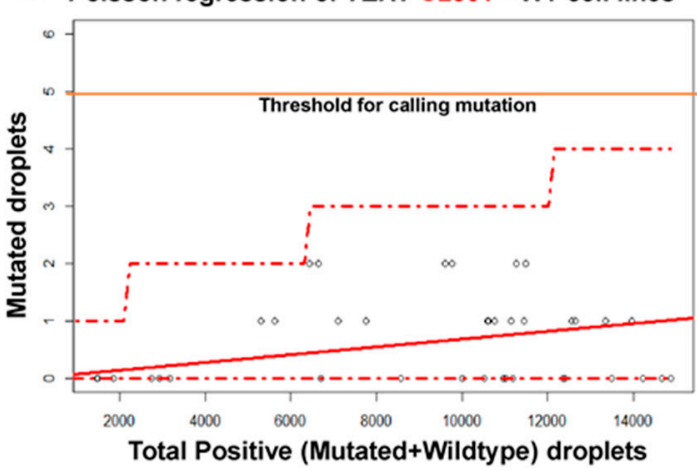

D. Poisson regression of TERT CC242-243TT - WT cell lines

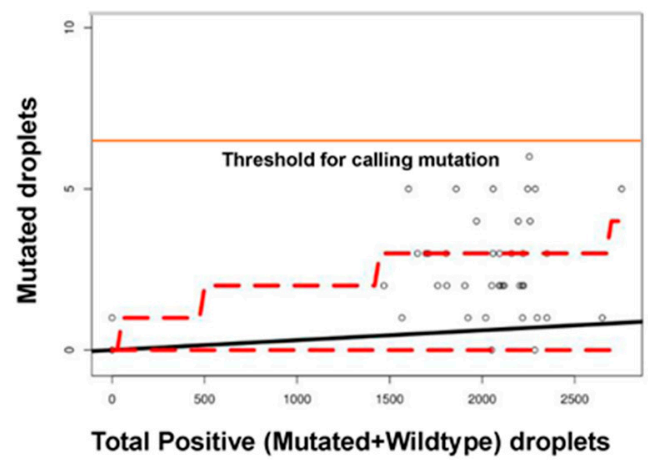

Figure 2. Determination of the threshold number of minimum droplets for calling a mutation. Poisson regression was generated from the number of droplets obtained from channel 1 (for mutated probe) and channel 2 (for wildtype probe) of 20 wildtype cell-lines for the C228T (A), C250T (B), C228A (C) and CC242-243TT (D) ddPCR assays. From this regression, the threshold for calling C228T, C250T, C228A and CC242-243TT mutations was set at 6, 5, 5 and 6 positive/mutated droplets, respectively.

\subsection{Determination of the Limit of Detection of the ddPCR Assays}

The limit of detection (LOD) of the ddPCR assays was evaluated using serial dilutions of DNA from TERT C228T and C250T mutated cell lines in a background of DNA samples wild-type for these two mutations as depicted in Section 4. Quantities of $5 \mathrm{ng}, 10 \mathrm{ng}, 20 \mathrm{ng}$ and $40 \mathrm{ng}$ template DNA from these serially diluted samples were used for the ddPCR assays and the mutant allele fraction (MAF) was calculated as a fraction of the number of droplets detected in the channel-specific for the probe detecting the mutated allele to that of the wild-type allele. Our results show that the LOD of the ddPCR assays is a function of the amount of template DNA used as an input for ddPCR experiments Tables S1 and S2. The LOD (lowest detectable MAF without false positive) for the TERT C228T assay was $2.45 \%, 0.69 \%$, and $0.18 \%$ for $10 \mathrm{ng}, 20 \mathrm{ng}$ and $40 \mathrm{ng}$ of template DNA, respectively (Table S1). An exception was observed for $5 \mathrm{ng}$ where the LOD was $0.6 \%$, probably because of a relatively low number of total positive droplets. On the other hand, the LOD for the TERT C250T assay was 1.96\%, $0.43 \%, 0.41 \%$ and $0.18 \%$ for $5 \mathrm{ng}, 10 \mathrm{ng}, 20 \mathrm{ng}$ and $40 \mathrm{ng}$ of template DNA, respectively (Table S2).

We could also determine the quantitative linearity of MAFs using this experiment. For this purpose, the experimentally determined ddPCR MAFs were plotted against the MAFs theoretically present in the serially diluted input DNA (Figures 3 and 4). The results showed that there was a strong correlation between the input MAFs and the MAFs calculated from the dAPCR experiments for both C228T and C250T assays and any amount of template DNA $\left(\mathrm{R}^{2}>0.95\right)$ (Figures 3 and 4$)$. 


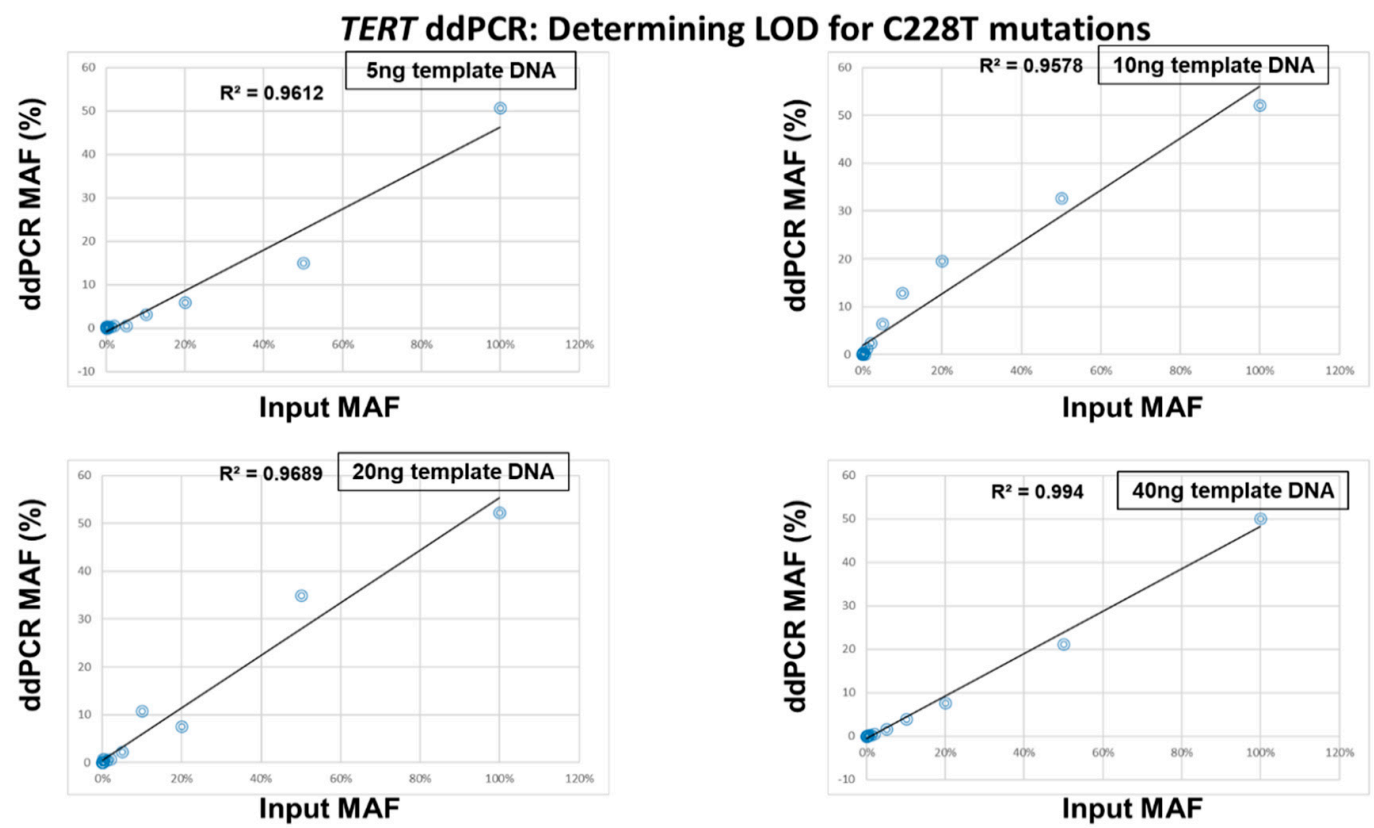

Figure 3. Linearity between the input Mutant Allelic Fractions (MAFs) and the experimentally determined MAFs for the TERT C228T assay. The theoretical percentage of MAFs from serially diluted C228T mutated template DNA into wild-type DNA was plotted against the experimentally determined ddPCR MAFs for $5 \mathrm{ng}, 10 \mathrm{ng}, 20 \mathrm{ng}$ and $40 \mathrm{ng}$.

TERT ddPCR: Determining LOD for C250T mutations
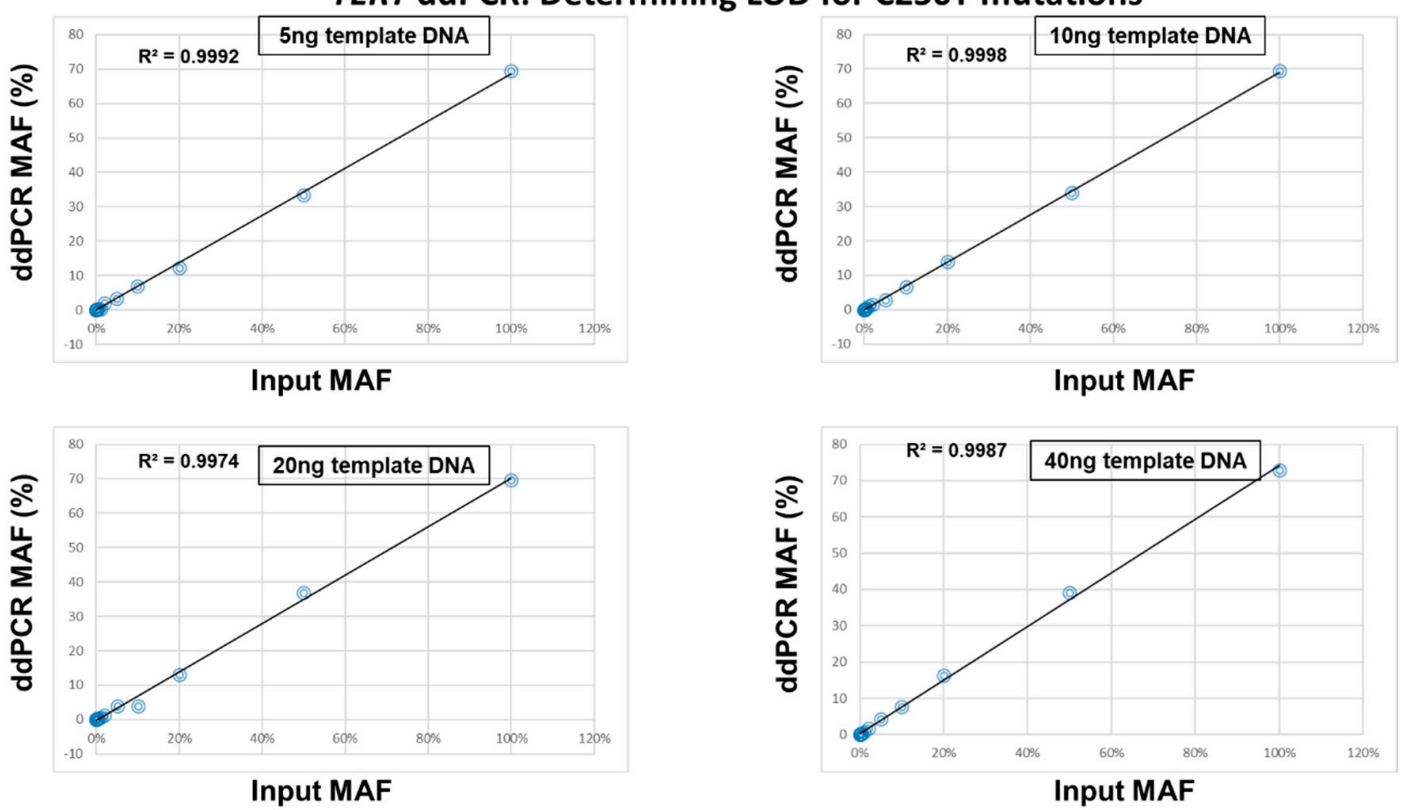

Figure 4. Linearity between the input Mutant Allelic Fractions (MAFs) and the experimentally determined MAFs for the TERT C250T assay. The theoretical percentage of the MAFs from serially diluted C250T mutated template DNA into wild-type DNA was plotted against the experimentally determined ddPCR MAFs for $5 \mathrm{ng}, 10 \mathrm{ng}, 20 \mathrm{ng}$ and $40 \mathrm{ng}$.

2.4. Comparison of the ddPCR and UroMuTERT Assays for the Detection of TERT Promoter Mutations in Urinary and Tumor DNA

We performed the ddPCR assays for $\mathrm{C} 228 \mathrm{~T}$ and $\mathrm{C} 250 \mathrm{~T}$ on all the samples with a sufficient quantity of urinary DNA from the DIAGURO ( $n=89 / 93$ cases and $n=92 / 94$ controls; US cfDNA or UP cellDNA) 
and the IPO-PORTO ( $n=49 / 50$ cases and $n=50 / 50$ controls; UP cellDNA) series. All available tumors from the DIAGURO $(n=81)$ were also screened by ddPCR assays. Additionally, we validated the UroMuTERT NGS results for the C228A and CC242-243TT mutations in samples that were positive for these mutations.

In the DIAGURO series, the sensitivity and specificity of the ddPCR assays (C228T or C250T mutations) for detecting UC using either US cfDNA or UP DNA was 86.8\% (95\% CI 80.3-94.5) and 92.4\% (95\% CI 85.0-96.9), respectively (Table 1). Details about the availability of the samples or data related to the screening of US cfDNA and UP cellDNA individually are given in Table S3, together with related sensitivity and specificity. The overall sensitivity of the ddPCR assays (C228T or C250T mutations) in detecting primary UC cases in urine cellDNA from the IPO-PORTO cohort was 67.4\% (95\% CI 52.5-80.1) with a specificity of 100.0\% (95\% CI 92.9-100.0) (Table 1). We assessed the ddPCR analytical sensitivity of detecting urinary mutations in $81 \mathrm{BC}$ cases with available matched tumors and identified urinary TERT promoter mutation(s) in US or UP in 69 of the 71 TERT mutated tumors (analytical sensitivity of 97.2\%; 95\% CI 90.2-99.7). Of the 10 tumors without TERT promoter mutations, seven were also negative in urine samples, three were positive for C228T in US or UP. In our previous study, we have established a single-gene assay based on the Ion Torrent Proton system (UroMuTERT) for the quantification of tumor-derived TERT promoter mutations load in urine cellDNA or cell-free DNA and evaluated its clinical performance in the DIAGURO and IPO-PORTO case-control studies [11]. Here, we compared the sensitivity, specificity, and accuracy of urinary TERT promoter mutations ddPCR assays for the detection of UC to that of UroMuTERT assay using the whole set of data ( $n=187$ in the DIAGURO and $n=100$ in IPO-PORTO series) [11] and a restricted set of samples with available data for both techniques ( $n=181$ in the DIAGURO and $n=99$ in IPO-PORTO series) (Table 1). We also compared the analytical sensitivity and specificity of detecting urinary TERT promoter mutations in corresponding matched tumors of DIAGURO cases $(n=81)$ using the two evaluated approaches.

Considering the latter condition, of the 32 IPO-PORTO BC cases detected with UroMuTERT, ddPCR assays confirmed the presence of the mutation in 30 cases and enabled the detection of two BC cases initially negative by UroMuTERT, suggesting a slightly increased sensitivity $(67.4 \%$ with ddPCR vs. $65.3 \%$ with UroMuTERT). This was not observed in the DIAGURO series where, of the 80 BC cases detected with UroMuTERT, two were not confirmed by ddPCR assays, whereas one initial False-negative with UroMuTERT turned positive (sensitivity of $86.80 \%$ with ddPCR vs. $90.7 \%$ with UroMuTERT). Of note, the UroMuTERT sensitivity increased as compared to the previous published data involving $93 \mathrm{BC}$ cases $(87.1 \%$ ) because three out of $12 \mathrm{BC}$ cases without mutation after UroMuTERT could not be tested by ddPCR assays. The $100 \%$ specificity observed in the 50 IPO-PORTO controls after UroMuTERT held true with ddPCR assays, whereas of the 92 DIAGURO controls evaluated by ddPCR, seven false positives were identified with ddPCR and three by UroMuTERT (specificity of $92.4 \%$ versus $95.6 \%$, respectively). Restricting the analysis to the 81 tumor DNA samples of the DIAGURO series screened by ddPCR did not change the UroMuTERT analytical sensitivity previously reported in 83 tumor DNA samples (analytical sensitivity of 98.6\%; 95\% CI 92.5-99.96) [11], which was comparable to the ddPCR analytical sensitivity $(97.2 \% ; 95 \%$ CI 90.2-99.7). The number of cases without TERT promoter mutations in tumors and with positive $(n=3)$ and negative $(n=7)$ urine tests remained unchanged between the two approaches. Regardless of the case and control status, we observed an almost perfect agreement between the two methods for both US cfDNA ( $n=164$; kappa coefficient of 0.91 ) and UP cellDNA ( $n=280$; kappa coefficient of 0.94 ) (Table S4). The almost perfect agreement held true for tumor DNA samples of the DIAGURO cases $(n=81$; kappa coefficient of 0.95$)$. Altogether, our results indicate that the two methods developed at our laboratory (ddPCR and UroMuTERT) for detecting urinary or tumor TERT promoter mutations are comparable and that the discrepancies relate to the detection of low-allelic fraction TERT promoter mutations (of 1\% or less) in DNA in one of the two approaches. 
Table 1. Performance of urinary TERT promoter mutations in detecting UC by ddPCR and UroMuTERT Assays.

\begin{tabular}{|c|c|c|c|c|c|c|}
\hline \multirow{3}{*}{$\begin{array}{l}\text { C228T or C250T } \\
\text { Mutations }\end{array}$} & \multicolumn{2}{|c|}{ ddPCR Assays } & \multicolumn{4}{|c|}{ UroMuTERT Assay } \\
\hline & DIAGURO Cohort & PORTO Cohort & DIAGURO Cohort a & PORTO Cohort a & DIAGURO Cohort b & PORTO Cohort b \\
\hline & US cfDNA or UP DNA & UP DNA & US cfDNA or UP DNA & UP DNA & US cfDNA or UP DNA & UP DNA \\
\hline Total Number analyzed & $(n=181)$ & $(n=99)$ & $(n=181)$ & $(n=99)$ & $(n=187)$ & $(n=100)$ \\
\hline True Positive-no & 79 & 33 & 80 & 32 & 81 & 33 \\
\hline True Negative-no & 85 & 50 & 88 & 50 & 89 & 50 \\
\hline False Positive-no & 7 & 0 & 4 & 0 & 5 & 0 \\
\hline False Negative-no & 10 & 16 & 9 & 17 & 12 & 17 \\
\hline Sensitivity (95\% CI)-\% & $86.8(80.3-94.5)$ & $67.4(52.5-80.1)$ & $90.7(83.1-95.7)$ & $65.3(50.4-78.3)$ & $87.1(78.6-93.2)$ & $66.0(51.2-78.8)$ \\
\hline Specificity (95\% CI)-\% & $92.4(85.0-96.9)$ & $100.0(92.9-100.0)$ & $95.6(89.2-98.8)$ & $100.0(92.9-100.0)$ & $94.7(88.0-98.3)$ & $100.0(92.9-100.0)$ \\
\hline Accuracy (95\% CI)-\% & $91.3(86.2-95.0)$ & $90.2(82.6-95.3)$ & $93.1(88.5-96.3)$ & $89.6(81.8-94.8)$ & $92.4(90.6-94.0)$ & $89.8(87.8-91.6)$ \\
\hline
\end{tabular}

a: Data from Avogbe et al. [11], with the samples screened with both ddPCR and UroMuTERT assays. Samples with not enough DNA or ddPCR data were excluded for a precise comparison of the performance of the two methods ( $n=6$ from the DIAGURO series and $n=1$ from the IPO-PORTO cohort). b: Original data from Avogbe et al. [11]. 
2.5. Assessment of the Interrater Reliability of ddPCR and UroMuTERT Assays in Detecting Urinary TERT Promoter Mutations

While an almost perfect agreement between the two methods was shown in the two case-control studies, we further investigated whether it was maintained in a large series of serial urine samples from follow-up BC cases $(n=394)$ where we expected a fraction of samples to carry low MAF TERT promoter mutations. We screened US cfDNA and UP cellDNA samples for TERT promoter mutations with the two diagnostic approaches and calculated the kappa coefficients for all samples, for US cfDNA and UP cellDNA separately and we further stratified samples according to various level of MAFs obtained from the ddPCR data (Table 2). A strong agreement was also observed in this large series of urine samples (kappa coefficient of 0.85 ), regardless of urine DNA types (kappa coefficient of 0.89 for US cfDNA and of 0.85 for UP cellDNA). The highest kappa coefficient (0.99) was seen for samples with MAFs $>2 \%$ but the agreement between the two methods was considered as moderate for samples with MAFs $<2 \%$ (0.78) and for samples with MAFs < $1 \%(0.7)$. However, the agreement was minimal for the samples with the lowest MAFs ( $<0.5 \%$; kappa coefficient 0.32$)$ indicating that discrepancies between the mutational calls between the two methods are more likely to occur in samples with very-low MAFs, which confirms the observations made in the case-control studies (Table 2).

Table 2. Interrater reliability of ddPCR and UroMuTERT assays in detecting urinary TERT promoter mutations in a large series of serial urine samples from follow-up BC cases.

\begin{tabular}{|c|c|c|c|c|c|}
\hline \multirow{3}{*}{ Sample Type } & \multicolumn{2}{|c|}{ UroMuTERT-MUT } & \multicolumn{2}{|c|}{ UroMuTERT-WT } & \multirow{2}{*}{ Kappa Coefficient } \\
\hline & ddPCR-MUT & ddPCR-WT & ddPCR-MUT & ddPCR-WT & \\
\hline & $n$ & $n$ & $n$ & $n$ & \\
\hline $\begin{array}{l}\text { All Follow-up cases (UP } \\
\text { cellDNA and US cfDNA) }\end{array}$ & 173 & 10 & 15 & 196 & 0.87 \\
\hline All US cfDNA Follow-up cases & 86 & 3 & 9 & 123 & 0.89 \\
\hline All UP cellDNA Follow-up cases & 87 & 7 & 6 & 73 & 0.85 \\
\hline $\begin{array}{c}\text { Cases US/UP follow-up with } \\
\text { MAF }<2 \% \text { ddPCR }\end{array}$ & 64 & 10 & 14 & 73 & 0.78 \\
\hline $\begin{array}{c}\text { Cases US/UP follow-up with } \\
\text { MAF }>2 \% \text { ddPCR }\end{array}$ & 109 & 0 & 1 & 123 & 0.99 \\
\hline $\begin{array}{c}\text { Cases US/UP follow-up with } \\
\text { MAF }<1 \% \text { ddPCR }\end{array}$ & 18 & 7 & 4 & 73 & 0.70 \\
\hline $\begin{array}{c}\text { Cases US/UP follow-up with } \\
\text { MAF }>1 \% \text { ddPCR }\end{array}$ & 155 & 3 & 11 & 123 & 0.90 \\
\hline $\begin{array}{l}\text { Cases US/UP follow-up with } \\
\text { MAF }<0.5 \% \text { ddPCR }\end{array}$ & 3 & 7 & 3 & 73 & 0.32 \\
\hline $\begin{array}{l}\text { Cases US/UP follow-up with } \\
\text { MAF }>0.5 \% \text { ddPCR }\end{array}$ & 170 & 3 & 12 & 123 & 0.90 \\
\hline
\end{tabular}

US: Urine Supernatant. UP: Urine Pellet. MAF: Mutant Allelic Fraction.

\subsection{Correlation of MAFs between ddPCR and UroMuTERT Assays}

Based on test results obtained from the two approaches on urine samples of the two case-control studies and on US cfDNA $(n=172)$ and UP cellDNA $(n=222)$ of the follow-up BC cases, we observed a strong correlation of urinary TERT promoter mutation MAFs for UP cell DNA $\left(r^{2}=0.94\right)$ and US cfDNA $\left(r^{2}=0.87\right)$, although the correlation was slightly less strong for the latter (Figure 5). For the same samples, the MAFs tended to be higher with the UroMuTERT assay than with the ddPCR assays.

Finally, in all evaluated urine samples from UC cases (including follow-up urine samples), the lowest TERT promoter MAF detected by ddPCR assays from $10 \mathrm{ng}$ DNA were $0.25 \%$ and $0.1 \%$ in UP cellDNA and $0.17 \%$ and $0.14 \%$ in US cfDNA for C228T and C250T assays, respectively. 

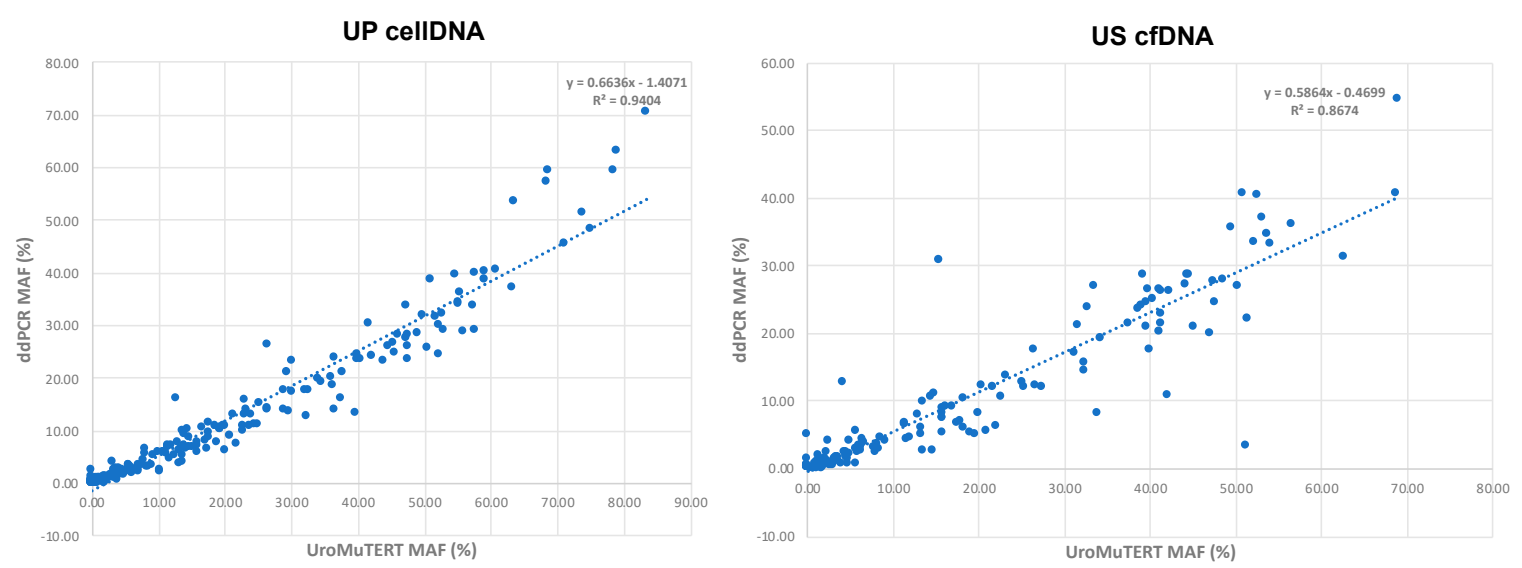

Figure 5. Correlation of TERT promoter Mutant Allelic Fractions (MAFs) between ddPCR and UroMuTERT assays in the two types of urinary DNA samples. Scatter plots of MAFs obtained by ddPCR and UroMuTERT assays run on US cfDNA ( $n=172$; left panel) and UP cellDNA ( $n=222$; right panel) from patients enrolled in the two case-control studies (DIAGURO and IPO-PORTO) and in the follow-up BC study.

\section{Discussion}

Owing to the presence of exfoliated cells from the urinary tract epithelium in urine, the latter represents the best reservoir of urinary DNA for the analysis of tumor-derived mutations in BC patients. While liquid biopsy presents an opportunity for non-invasive detection and monitoring of bladder cancer, there are still technological bars to be crossed [16-18]. Due to the dilution of tumor-derived cells with normal epithelial cells in the urine of BC patients, the fractional abundance of the tumor cells can be very low, thereby requiring highly sensitive method(s) for the detection of these urinary mutations [18]. Droplet digital PCR (ddPCR) assays presents some advantages in detecting low-allelic fraction mutations in the urine [19]. The performance of ddPCR assays in detecting TERT promoter mutations in urine cfDNA has only been reported in a limited series of UC cases and controls [17] and more recently in UC cases undergoing monitoring of post-therapy disease [19]. Few other studies assessed ddPCR assays for detecting TERT promoter mutations but in different cancer types including melanoma and glioma and in a very small sample set [20-22].

In this study, we developed sensitive ddPCR assays for the detection of urinary TERT promoter mutations in UC and report comparable performance with our previously developed NGS-based UroMuTERT assay [11]. TERT promoter mutations are the most common somatic mutations in UC and their detection in urine has significant clinical applications [11,18,23]. A study by Kinde et al., has showed that the somatic mutations in the TERT promoter detected after the transurethral resection of the bladder tumor (TURBT) could be potential biomarkers of recurrent UC [10]. Another study has shown an increased risk associated with the detection of these mutations and recurrence of pT1 bladder cancer [24] and a more recent one demonstrated that the post-therapy urinary C228T status in BC cases under surveillance for relapse matched the clinical observations [19] thereby suggesting a plausible way of non-invasive dynamic follow-up of non-muscle invasive bladder cancer patients. In addition, within a prospective cohort study, urinary TERT promoter mutations were detected up to 10 years prior to clinical diagnosis of primary bladder cancer and were absent from matched controls [12]. All these studies provide exciting evidence for the utility of urinary TERT promoter mutations as non-invasive biomarkers for bladder cancer detection and monitoring.

Various NGS-based assays have been developed over time for the detection of TERT promoter mutations in urine $[11,18]$. However, due to the involvement of sophisticated laboratory workflows, extensive bioinformatics post-processing and analysis of the data, the NGS-based assays are not broadly implemented in the clinic [25]. On the other hand, the advantages of the ddPCR assays are its superior sensitivity, fast processing time, independence from extensive bioinformatics post-processing, and 
analysis of the data $[26,27]$. In our study, the LOD tests using different amounts of serially diluted cell line template DNA showed that our assays could detect as low as $0.18 \%$ for the C250T and the C228T mutant DNA. Our results suggest that the LOD for these mutations using ddPCR assays is also influenced by the amount of input template DNA. The LOD proved to be lower when the amount of template DNA was increased from $5 \mathrm{ng}$ to $40 \mathrm{ng}$ DNA, confirming the findings of a recent study [28]. This LOD is slightly better than that of our previously developed UroMuTERT assay for which the limits of detection were $0.5 \%$ and $0.8 \%$ for the $\mathrm{C} 250 \mathrm{~T}$ and C228T mutations, respectively [11]. A recent study on ddPCR assays for detecting TERT promoter mutations in melanoma has shown a similar LOD using TERT mutated melanoma cell lines [22]. When applied to urine samples of UC cases, the lowest TERT promoter MAF detected by ddPCR assays from $10 \mathrm{ng}$ US cfDNA $(n=172)$ or UP cellDNA $(n=222)$ were equivalent to the LOD measured with cell-lines, demonstrating the transferability of the thresholds to such sample types. While the LOD of standard ddPCR assays for other common somatic mutations such as BRAF V600E could be as low as 0.001\% [29], the high GC content and repetitive sequences of the TERT promoter region makes it more difficult to get a clear separation of mutated droplets against the background noise [30].

We also observed that, for the same samples, the MAFs tended to be higher with the UroMuTERT assay than with the ddPCR assays. We postulated that the first PCR-based step of the UroMuTERT assay may preferentially amplify the mutated TERT allele as a result of incomplete denaturation of extremely high GC-rich heteroduplex fragments, thus resulting in higher MAFs than the ones observed with ddPCR assays, which is based on absolute quantification of the target and should therefore represent a more precise measurement of the MAFs than the ones measured by UroMuTERT. Furthermore, the urinary sample type may matter when comparing the MAF between the two methods and may explain the difference in the $\mathrm{R}^{2}$ for US cfDNA and UP cellDNA. Few more outliers of the regression were observed for US cfDNA than for UP cellDNA. This may be explained by the differences in the distribution of US mutated and wild-type cfDNA size profiles between samples and the differences in amplicon size between UroMuTERT (147bp) and ddPCR (64bp for C228T/A and 88bp for C250T and CC242-243TT) assays; the latter favoring the amplification of smaller thus highly degraded urinary cfDNA forms, which have been shown to be predominant in such sample [31]. Altogether, this may partly explain the minor discrepancies of low-level urinary TERT promoter mutations observed between the two methods. Indeed, in the urine pellet DNA (UP DNA) from the $\mathrm{BC}$ cases in the IPO-PORTO series, the ddPCR assays failed to replicate positive mutations calls for two samples analyzed with the UroMuTERT assay, but enabled the mutation detection in two additional BC cases initially negative with the UroMuTERT assay, keeping the overall sensitivity to the similar levels. For the DIAGURO series, the sensitivity of the ddPCR assays was slightly lower (by around $3 \%$ ) compared to the UroMuTERT assays. However, this decreased sensitivity of the ddPCR assays could be due to the fact that three out of $12 \mathrm{BC}$ cases without mutation after UroMuTERT could not be tested by ddPCR assays. While the 100\% specificity observed in the IPO-PORTO series was found for both the UroMuTERT and ddPCR assays, the specificity of the ddPCR assays in the DIAGURO controls was lowered compared to UroMuTERT (specificity of $92.4 \%$ versus $95.6 \%$, respectively). While applying a more strict interpretation of the Cohen's kappa coefficient developed by McHugh to better reflect the level of agreement between two methods in health-related studies [32], an almost perfect agreement was still observed between ddPCR assays an UroMuTERT for both US cfDNA $(n=164$; kappa coefficient of 0.91$)$ and UP cellDNA ( $n=280$; kappa coefficient of 0.94$)$. This was confirmed in a large independent series of serial urine samples from follow-up BC cases, in which, when stratified by MAF, the agreement remains almost perfect for samples with MAFs $>2 \%$ (kappa coefficient of 0.99) but dropped to moderate for samples with MAF $<1 \%$ and to minimal for the samples with the lowest MAFs $(<0.5 \%)$, indicating higher rates of false positive or false negative calls in samples with very-low MAFs. Finally, there was also an almost perfect agreement between UroMuTERT and ddPCR assays for the detection of the mutations in the tumors, further attesting to the robustness of the two methods. In addition, we observed a high concordance of mutational status between tumors and 
matched urine samples in DIAGURO BC cases with analytical sensitivities of $98.6 \%$ for UroMuTERT and $97.2 \%$ for ddPCR assays and therefore only a small fraction of false negatives, likely reflecting in such cases the existence of minor tumoral TERT mutated clones (MAF < 1\%) undetectable in urine samples. Bladder tumors are characterized by intra- and inter- tumoral heterogeneity both at the molecular and cellular levels $[33,34]$. The co-existence of multiple sub-clonal populations, including multiple TERT mutated clones has been also reported in bladder tumors [11,24]. As urine represents of 'screenshot' of the bladder tumor heterogeneity, tumor-derived mutations may be detected in urine that would not necessarily be captured by a unique piece of biopsy due to the heterogenous nature of this cancer type. This was observed in three out of ten DIAGURO cases with wild-type biopsy, highlighting the superiority of urine over biopsy in reflecting mutational burden of heterogenous bladder tumors. This observation further supports the importance of implementing testing for urinary TERT promoter mutations for the detection of BC with well validated methodologies.

In conclusion, the two methods developed at our laboratory (ddPCR and UroMuTERT) for detecting urinary TERT promoter mutations are comparable. The high sensitivity and specificity of the ddPCR urinary TERT promoter mutations assays in the two independent cohorts investigated in this study provides evidence that these tests could be easily implemented into the clinic for the non-invasive detection of bladder cancer.

\section{Materials and Methods}

\subsection{Study Population, Sample Collection and Processing}

The urine and tumor samples used in this study were from participants who were recruited as a part of two separate case-control studies: the DIAGURO and IPO-PORTO case-control series. Both of the studies were approved by the relevant ethical review committees (IARC Ethics Committee, ethical approvals No. 15-23 and No. 15-23-A1) and written informed consent was obtained for all participants. The details of these two case-control series are described elsewhere [11]. Briefly, the DIAGURO case-control study included patients with post-surgery histological confirmation of primary or recurrent UC (BC or/and Upper tract urothelial cell carcinoma (UTUCC) at any stage and grade) as cases $(n=93)$ and patients with urological pathological conditions other than UC as controls $(n=94)$. Tumor-urine-blood trios for cases and urine-blood duos for controls were collected prospectively in appropriate collection tubes. The blood and urine samples were processed within two hours of collection and DNA from plasmas, white blood cells (WBC), urine supernatants (US), urine pellets (UP), and tumor tissues were extracted using standard protocols [11]. Histological review of the tumor tissues was performed by a qualified pathologist. The IPO-PORTO case-control replicative series included cellDNA from urine pellets of 50 primary BC cases and 50 healthy controls with no history of cancer. The samples were part of the Biobank of the Portuguese Oncology Institute of Porto. The follow-up of the DIAGURO cases with non-muscle invasive UC is currently being organized for 56 patients with a collection of urine samples (US and UP) at each medical examination during medical surveillance for recurrence. Samples were processed and stored as described in the previous study and at the time of the present study, 394 urine samples were screened with UroMuTERT following the same protocol as previously described [11] and with ddPCR as described below.

\subsection{Detection of TERT Promoter Mutations Using ddPCR Assay}

We have developed and validated droplet digital PCR (ddPCR) assays for all the four TERT promoter somatic mutations found in our previous study using the UroMuTERT assay as previously described [11]. The targeted mutations include the most prevalent C228T and C250T, as well as the rare C228A, CC242-243TT mutations (Table S5, Figure S1).

For each ddPCR assay, 5'-FAM or 5'-HEX reporter dye and 3' Iowa Black Fluorescent quencher were designed (Biorad, Hercules, California, USA). We selected positive samples with known TERT promoter mutations and tested our experimental conditions. A $22 \mu \mathrm{L}$ reaction mix was prepared 
using $10 \mathrm{ng}$ of DNA was used as a template, $11 \mu \mathrm{L}$ of $2 \mathrm{x}$ ddPCR supermix-no dUTP (Biorad), $1.1 \mu \mathrm{L}$ of 20× FAM and HEX probes for mutated and wildtype alleles, $1.1 \mu \mathrm{L}$ of RsaI restriction enzyme $(10 \mathrm{U} / \mu \mathrm{L})$ and $0.2 \mu \mathrm{L}$ of 7 -deaza-dGTP, Li-salt $(2 \mu \mathrm{M})$. The droplets were generated using the autoDG droplet generator (Biorad). The PCR amplifications of the droplets were carried out separately for the C228T, C228A, CC242-243TT and C250T assays using the following PCR conditions: $95^{\circ} \mathrm{C}$ for $10 \mathrm{~min}$, 40 cycles of $94{ }^{\circ} \mathrm{C}$ for $30 \mathrm{~s}$, ramp $2.5 / \mathrm{s}, 54{ }^{\circ} \mathrm{C}$ for C228T assay $\left(55^{\circ} \mathrm{C}\right.$ for the C228A and CC242-243TT, $64{ }^{\circ} \mathrm{C}$ for C250T assay; Figures S2 and S3) for $30 \mathrm{~s}$ followed by $98^{\circ} \mathrm{C}$ for $10 \mathrm{~min}$ and then kept at hold at $12{ }^{\circ} \mathrm{C}$. The fluorescent intensity of each droplet was measured using the droplet reader QX200 (Biorad). Analysis of ddPCR data was performed using QuantaSoft ${ }^{\mathrm{TM}}$ Analysis Pro1.0.596 software (Biorad). The preparation of the droplets using the AutoDG, the subsequent PCR amplification, and the measurement of the fluorescent intensity using the QX200 droplet reader were performed in three separate rooms specific for these respective purposes to ensure a contamination-free environment. The 2D amplitude plots from the QuantaSoft ${ }^{\mathrm{TM}}$ analysis pro software were analyzed by setting the threshold amplitudes for both the mutated and wild type channels. The thresholds for the channel 1 (mutated probe) for the C228A, C228T, CC242-243TT and C250T probes were 700, 1500, 500 and 3500, respectively. For the channel 2 (wild-type probe) the thresholds for C228A, C228T, CC242-243TT, and C250T probes were 1250, 1750, 1440, and 2000, respectively (Figure 1).

Two important technical aspects of developing ddPCR assays are the determination of the threshold number of droplets in the channel detecting the probe for the mutant allele and the limit of detection of the assays. Figure 6 explains the strategy for addressing these two points.

\section{Workflow for TERT ddPCR Assays: Test of Sensitivity}
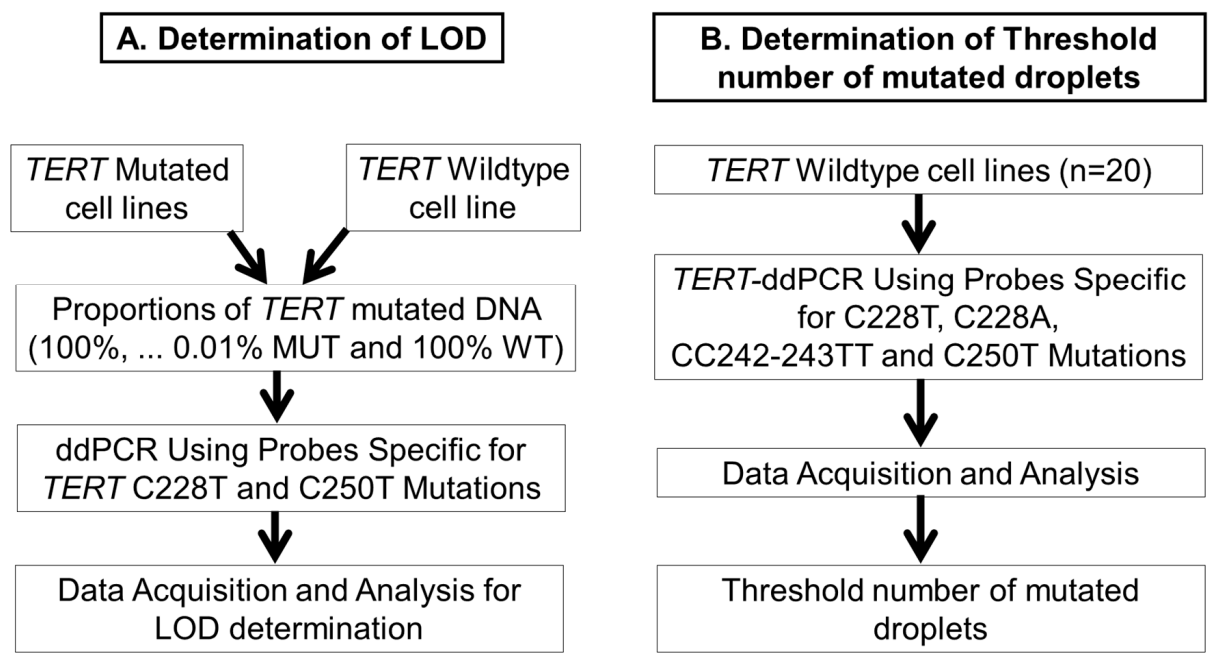

Figure 6. Schematic representation of the strategies for determining (A) the limit of detection (LOD) and (B) the threshold number of mutated droplets to call a mutation.

\subsection{Determination of the False-Positive Measures and Threshold Number of Minimum Mutated Droplets to Call a Mutation}

As recommended by the Clinical and Laboratory Standards Institute (CLSI) guidelines, negative samples should be measured to assess the probability distribution function of false-positive events detected in negative control samples [35]. With regards to ddPCR assays, one important technical aspect is to set up, for each assay, the threshold number of droplets in the channel detecting the probe for the mutant allele for calling a mutation beyond the background number of false-positive droplets. In order to determine the threshold number of positive droplets for calling a mutation, the ddPCR assays for the C228T, C228A, CC242-243TT and C250T mutations were performed on a series of cell lines which are wild-type at these genomic positions. The 2D amplitude plots from the QuantaSoft ${ }^{\mathrm{TM}}$ 
analysis pro software were analyzed by setting the threshold amplitudes for both the mutated and wild type channels. The defined signal thresholds for the channels 1 and 2 for the C228A, C228T, CC242-243TT and C250T probes were used (Figure 7). Then Poisson regression of the number of droplets above the threshold was generated from the count of channel 1 (for mutated probe) and of channel 2 (for wildtype probe).
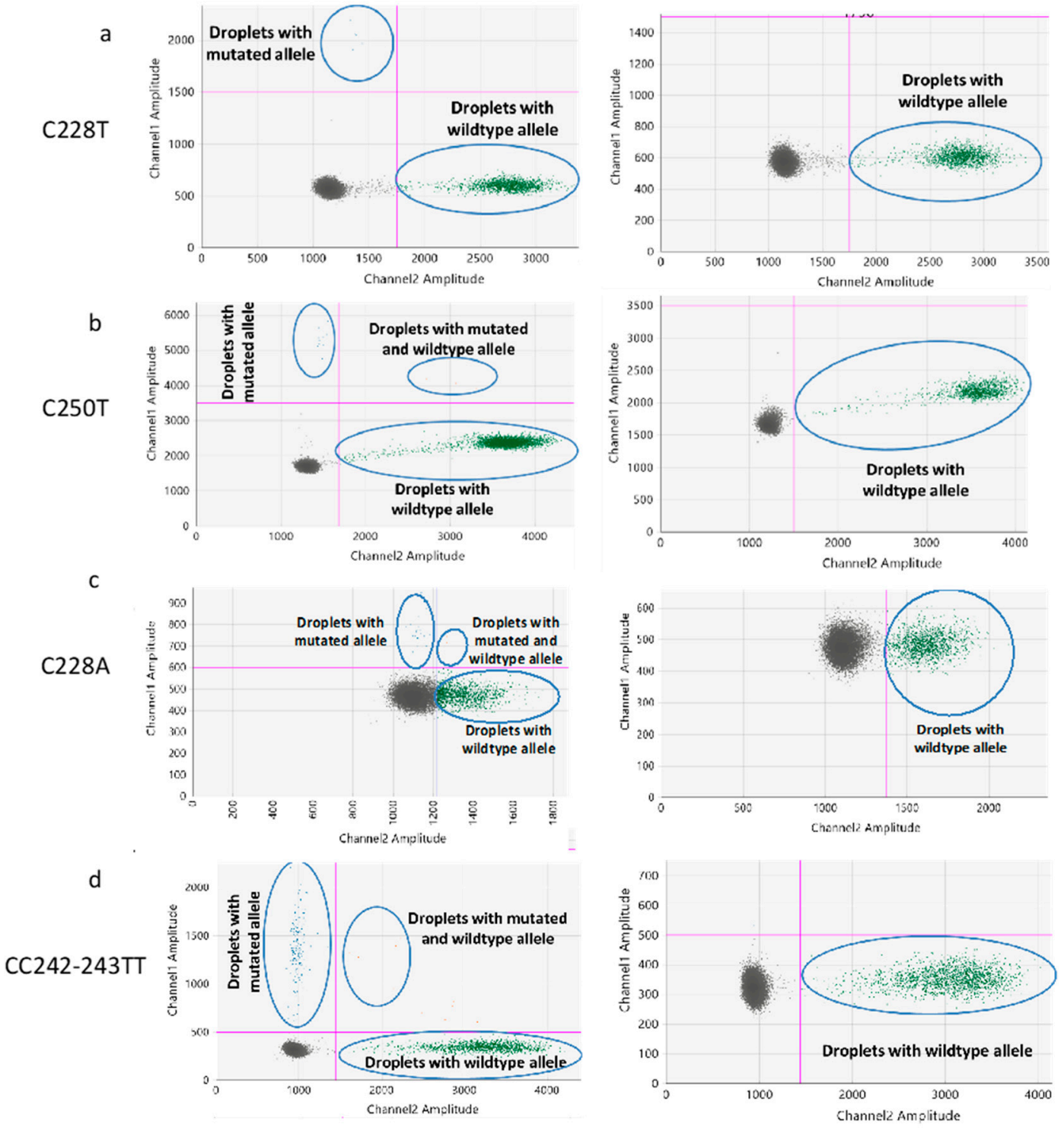

Figure 7. Examples of 2D scatterplots obtained from TERT promoter mutation ddPCR assays in representative samples. Assays testing for C228T (a), C250T (b), C228A (c), and CC242-243TT (d) mutations are displayed in four examples of mutated samples (left panels) and in four examples of wild-type samples (right panels). In the left panel, fluorescent probes (FAM) detect respective mutations as exemplified by the count of droplets with mutated alleles, while in the right panel, wild- type samples do not show any positive droplets (FAM) above the threshold line but show droplets with HEX fluorescence associated with wild-type probes. The pink lines are the thresholds for channel 1 (mutated probe) and channel 2 (wild-type probe) for the ddPCR mutation assays.

\subsection{Determination of the Limit of Detection of the ddPCR Assays}

Since the ddPCR assays are capable of detecting very low allelic-fraction mutations, another important technical development was to evaluate the limit of detection (LOD) of the TERT-ddPCR 
assays. To determine the LOD of the C228T and C250T assays, cell lines with characterized C228T and C250T TERT promoter mutations (HepG2 and A375, respectively) were used. Briefly, the genomic DNA from the HepG2 and A375 cell lines were serially diluted into TERT-wildtype DNA obtained from white blood cells of healthy controls to achieve from $100 \%$ cell lines DNA to $0 \%$ mutant allele fractions. Each of the serially diluted samples was tested using the respective ddPCR assays using the conditions mentioned above.

4.5. Comparison of the ddPCR and UroMuTERT Assays for the Detection of TERT Promoter Mutations in the Urine Samples of UC Cases and Controls

All the samples from the DIAGURO and IPO-PORTO series with a sufficient amount of urinary DNA after the UroMuTERT assay was previously performed, were analyzed using the ddPCR assays and the results were compared to those of the UroMuTERT assay [11]. For this, we used $10 \mathrm{ng}$ of urinary DNA (urine pellet or urine supernatant) as a template in a $22 \mu \mathrm{L}$ reaction as described above (Figure 8). The fluorescent intensity of each droplet was measured using the droplet reader QX200 (Biorad). Analysis of ddPCR data was performed using QuantaSoft ${ }^{\mathrm{TM}}$ Analysis Pro1.0.596 software (Biorad). All laboratory analyses were conducted blindly to the case or control status of the samples.

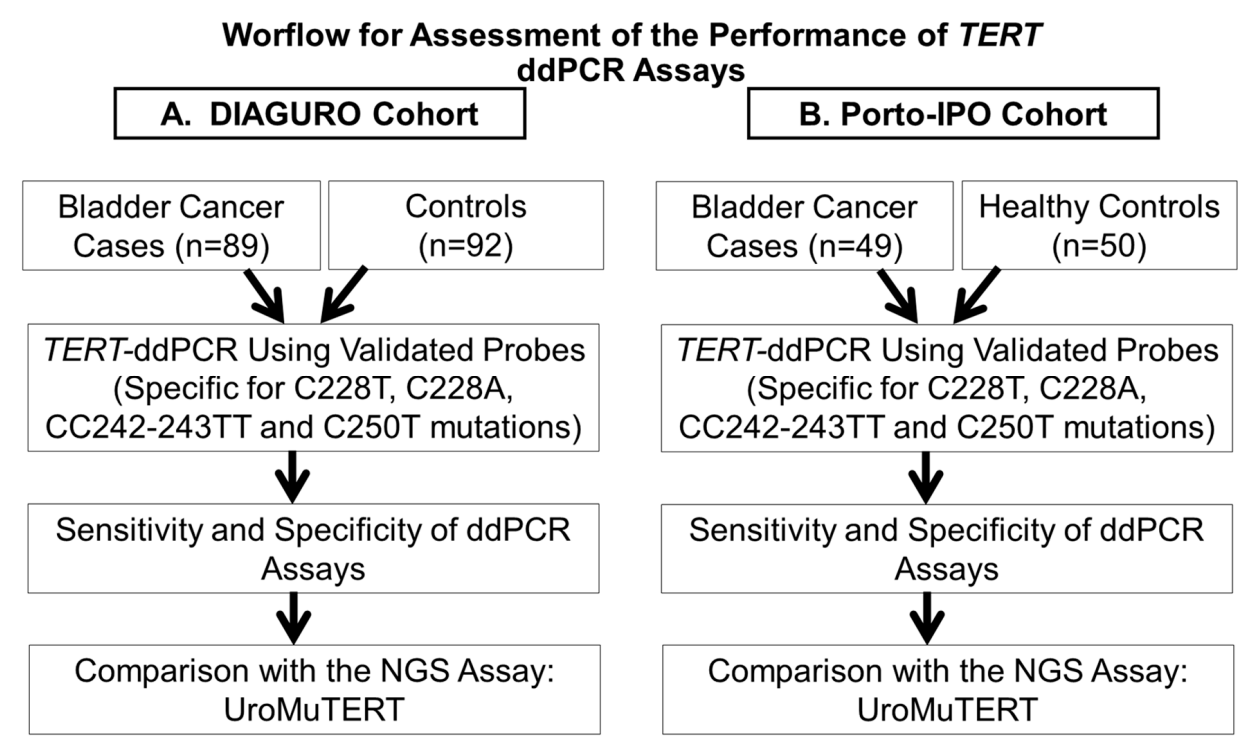

Figure 8. Schematic representation of the workflow for assessing the performance of the ddPCR assays for detecting TERT promoter mutations in urine of bladder cancer patients and controls in two independent cohorts.

\subsection{Statistical Analysis}

Clinical sensitivity, specificity, and accuracy of the urinary TERT promoter mutations were calculated for the detection of BC using UroMuTERT or ddPCR assays and their confidence intervals computed using the Clopper-Pearson method [36]. True positives were defined as BC cases with a positive TERT urine test (ddPCR or UroMuTERT); False positives as subjects with a positive TERT urine test and no evidence of BC; False negative as BC cases with a negative TERT urine test and True negatives as subjects with a TERT negative test and no evidence of $\mathrm{BC}$. The agreement between ddPCR and UroMuTERT assays was evaluated using Cohen's kappa index which indicates the proportion of agreement beyond that expected by chance [37]. Cohen suggested interpretation to categorize the kappa index, where $<0.00$ is a poor agreement, $0-0.2$ is a slight agreement, $0.21-0.40$ is a fair agreement, $0.41-0.60$ is a moderate agreement, $0.61-0.80$ is a substantial agreement, and $0.81-1.00$ is an almost perfect agreement has been suggested to be too lenient for health-related studies [32]. We, therefore, used McHugh's interpretation of the Cohen's kappa index to infer the level of agreement between the 
two tested methods for mutations detection, where $0-0.2$ is none agreement, $0.21-0.39$ is a minimal agreement, $0.40-0.59$ is a weak agreement, $0.60-0.79$ is a moderate agreement, $0.80-0.90$ is a strong agreement and $>0.9$ is an almost perfect agreement [32].

\section{Conclusions}

Both ddPCR-based and NGS-based (UroMuTERT) assays established for the detection of urinary TERT promoter mutations demonstrated good and comparable performance for the non-invasive detection of urothelial cancer. Interrater reliability analysis showed a strong agreement between the two methods and an almost perfect agreement for mutant allelic fractions above $2 \%$. Some discrepancies are however observed for the detection of low-allelic fraction mutations. The technical and analytical simplicity of ddPCR assays over the NGS-based assays could ease the future clinical implementation of the non-invasive tests for the detection and monitoring of urothelial cancer.

Supplementary Materials: The following are available online at http://www.mdpi.com/2072-6694/12/12/3541/s1, Figure S1: The TERT core promoter region with the primer and probe sets shown for each of the assays, Figure S2: 1D amplitude plot for Channel 1 (respective to mutated probe) and Channel2 (respective for wildtype probe) for the C228T assay at different annealing temperatures, Figure S3: 1D amplitude plot for Channel1 (respective to mutated probe) and Channel2 (respective for wildtype probe) for the C250T assay at different annealing temperatures, Table S1: Determination of Limit of Detection for the C228T mutations using cell line DNA, Table S2: Determination of Limit of Detection for the C250T mutations using cell line DNA, Table S3: Performance of urinary TERT promoter mutations in detecting UC by ddPCR based method, Table S4: Concordance of TERT promoter mutations status in urinary DNA of the DIAGURO and IPO-PORTO case-control studies Table S5: Probes for detecting C228T and C250T mutations in the ddPCR assay.

Author Contributions: Conceptualization, M.I.H., F.L.C.-K. and M.Z.; methodology M.I.H., F.L.C.-K. and M.Z.; software, M.I.H., C.V., T.M.D., M.F., G.S., J.D.M., F.L.C.-K. and M.Z.; validation, N.F., G.D., S.B., P.H.A., O.L., P.F., A.B., E.P., and A.R.O.S.E.S.; formal analysis, M.I.H., C.V., F.L.C.-K. and M.Z.; investigation, A.M., E.V., S.M., B.D.T., G.P., G.S. and F.L.C.-K.; resources, A.M., E.V., S.M., B.D.T., G.P., S.M.-R., R.H., C.J. and J.M.K.; data curation, N.F., G.D., C.V., S.B., P.H.A., O.L., P.F., A.B., and A.R.O.S.E.S.; writing-original draft preparation, M.I.H., F.L.C.-K. and M.Z.; writing - review and editing, N.F., C.V., S.B., P.H.A., M.F., E.V., A.B., E.P., A.R.O.S.E.S., G.B. and C.J.; supervision, F.L.C.-K. and M.Z.; project administration, F.L.C.-K. and M.Z.; funding acquisition, F.L.C.-K. and M.Z. All authors have read and agreed to the published version of the manuscript.

Funding: The work reported in this paper was undertaken during the tenure of M.I.H.'s postdoctoral fellowship from the International Agency for Research on Cancer. The research project was funded by the French Cancer League. S.B., T.M.D., S.M., O.L., P.F. and A.B. were supported by the French Cancer League. M.Z. and E.P. were supported by the Russian Foundation for Basic Research (grant no. 18-29-08040). The funders had no role in study design, collection, analysis, and interpretation of data, in manuscript writing or in submission process for publication.

Conflicts of Interest: Where authors are identified as personnel of the International Agency for Research on Cancer/World Health Organization, the authors alone are responsible for the views expressed in this article and they do not necessarily represent the decisions, policy or views of the International Agency for Research on Cancer/World Health Organization. The authors declare no conflict of interest.

\section{References}

1. Bray, F.; Ferlay, J.; Soerjomataram, I.; Siegel, R.L.; Torre, L.A.; Jemal, A. Global cancer statistics 2018: GLOBOCAN estimates of incidence and mortality worldwide for 36 cancers in 185 countries. CA Cancer J. Clin. 2018, 68, 394-424. [CrossRef]

2. Knowles, M.A.; Hurst, C.D. Molecular biology of bladder cancer: New insights into pathogenesis and clinical diversity. Nat. Rev. Cancer 2015, 15, 25-41. [CrossRef]

3. Yeung, C.; Dinh, T.; Lee, J. The health economics of bladder cancer: An updated review of the published literature. Pharmacoeconomics 2014, 32, 1093-1104. [CrossRef]

4. Blick, C.G.; Nazir, S.A.; Mallett, S.; Turney, B.W.; Onwu, N.N.; Roberts, I.S.; Crew, J.P.; Cowan, N.C. Evaluation of diagnostic strategies for bladder cancer using computed tomography (CT) urography, flexible cystoscopy and voided urine cytology: Results for 778 patients from a hospital haematuria clinic. BJU Int. 2012, 110, 84-94. [CrossRef] 
5. Gonzalez, A.N.; Lipsky, M.J.; Li, G.; Rutman, M.P.; Cooper, K.L.; Weiner, D.M.; Badalato, G.; Decastro, G.J.; Wenske, S.; McKiernan, J.M.; et al. The Prevalence of Bladder Cancer During Cystoscopy for Asymptomatic Microscopic Hematuria. Urology 2019, 126, 34-38. [CrossRef]

6. Kouba, E.; Lopez-Beltran, A.; Montironi, R.; Massari, F.; Huang, K.; Santoni, M.; Chovanec, M.; Cheng, M.; Scarpelli, M.; Zhang, J.; et al. Liquid biopsy in the clinical management of bladder cancer: Current status and future developments. Expert Rev. Mol. Diagn. 2020, 20, 255-264. [CrossRef]

7. Christensen, E.; Birkenkamp-Demtröder, K.; Nordentoft, I.; Høyer, S.; van der Keur, K.; van Kessel, K.; Zwarthoff, E.; Agerbæk, M.; Ørntoft, T.F.; Jensen, J.B.; et al. Liquid Biopsy Analysis of FGFR3 and PIK3CA Hotspot Mutations for Disease Surveillance in Bladder Cancer. Eur. Urol. 2017, 71, 961-969. [CrossRef]

8. Xylinas, E.; Kluth, L.A.; Rieken, M.; Karakiewicz, P.I.; Lotan, Y.; Shariat, S.F. Urine markers for detection and surveillance of bladder cancer. Urol. Oncol. 2014, 32, 222-229. [CrossRef]

9. Hosen, I.; Rachakonda, P.S.; Heidenreich, B.; de Verdier, P.J.; Ryk, C.; Steineck, G.; Hemminki, K.; Kumar, R. Mutations in TERT promoter and FGFR3 and telomere length in bladder cancer. Int. J. Cancer 2015, 137, 1621-1629. [CrossRef]

10. Kinde, I.; Munari, E.; Faraj, S.F.; Hruban, R.H.; Schoenberg, M.; Bivalacqua, T.; Allaf, M.; Springer, S.; Wang, Y.; Diaz, L.A., Jr.; et al. TERT promoter mutations occur early in urothelial neoplasia and are biomarkers of early disease and disease recurrence in urine. Cancer Res. 2013, 73, 7162-7167. [CrossRef]

11. Avogbe, P.H.; Manel, A.; Vian, E.; Durand, G.; Forey, N.; Voegele, C.; Zvereva, M.; Hosen, M.I.; Meziani, S.; De Tilly, B.; et al. Urinary TERT promoter mutations as non-invasive biomarkers for the comprehensive detection of urothelial cancer. EBioMedicine 2019, 44, 431-438. [CrossRef]

12. Hosen, M.I.; Sheikh, M.; Zvereva, M.; Scelo, G.; Forey, N.; Durand, G.; Voegele, C.; Poustchi, H.; Khoshnia, M.; Roshandel, G.; et al. Urinary TERT promoter mutations are detectable up to 10 years prior to clinical diagnosis of bladder cancer: Evidence from the Golestan Cohort Study. EBioMedicine 2020, 53, 102643. [CrossRef]

13. Micheli, E.; Martufi, M.; Cacchione, S.; De Santis, P.; Savino, M. Self-organization of G-quadruplex structures in the $h T E R T$ core promoter stabilized by polyaminic side chain perylene derivatives. Biophys. Chem. 2010, 153, 43-53. [CrossRef]

14. Monsen, R.C.; DeLeeuw, L.; Dean, W.L.; Gray, R.D.; Sabo, T.M.; Chakravarthy, S.; Chaires, J.B.; Trent, J.O. The hTERT core promoter forms three parallel G-quadruplexes. Nucleic Acids Res. 2020, 48, 5720-5734. [CrossRef]

15. Colebatch, A.J.; Witkowski, T.; Waring, P.M.; McArthur, G.A.; Wong, S.Q.; Dobrovic, A. Optimizing Amplification of the GC-Rich TERT Promoter Region Using 7-Deaza-dGTP for Droplet Digital PCR Quantification of TERT Promoter Mutations. Clin. Chem. 2018, 64, 745-747. [CrossRef]

16. Kouba, E.; Cheng, L. Clinical utility versus futility: A tipping point for liquid biopsies in bladder cancer. Future Oncol. 2019, 15, 3751-3753. [CrossRef]

17. Russo, I.J.; Ju, Y.; Gordon, N.S.; Zeegers, M.P.; Cheng, K.K.; James, N.D.; Bryan, R.T.; Ward, D.G. Toward Personalised Liquid Biopsies for Urothelial Carcinoma: Characterisation of ddPCR and Urinary cfDNA for the Detection of the TERT 228G>A/T Mutation. Bladder Cancer 2018, 4, 41-48. [CrossRef]

18. Satyal, U.; Srivastava, A.; Abbosh, P.H. Urine Biopsy-Liquid Gold for Molecular Detection and Surveillance of Bladder Cancer. Front. Oncol. 2019, 9, 1266. [CrossRef]

19. Pritchard, J.J.G.; Hamilton, G.; Hurst, C.D.; Fraser, S.; Orange, C.; Knowles, M.A.; Jones, R.J.; Leung, H.Y.; Iwata, T. Monitoring of urothelial cancer disease status after treatment by digital droplet PCR liquid biopsy assays. Urol. Oncol. 2020, 38, 737.e1-737.e10. [CrossRef]

20. Ge, J.; Liu, M.Y.; Li, L.; Deng, Q.; Liu, F.; Luo, Y.; Wang, L.; Yao, G.; Zhu, D.; Lu, H.; et al. Detection of IDH1 and TERT promoter mutations with droplet digital PCR in diffuse gliomas. Int. J. Clin. Exp. Pathol. 2020, 13, 230-238.

21. McEvoy, A.C.; Calapre, L.; Pereira, M.R.; Giardina, T.; Robinson, C.; Khattak, M.A.; Meniawy, T.M.; Pritchard, A.L.; Hayward, N.K.; Amanuel, B.; et al. Sensitive droplet digital PCR method for detection of TERT promoter mutations in cell free DNA from patients with metastatic melanoma. Oncotarget 2017, 8 , 78890-78900. [CrossRef]

22. McEvoy, A.C.; Wood, B.A.; Ardakani, N.M.; Pereira, M.R.; Pearce, R.; Cowell, L.; Robinson, C.; Grieu-Iacopetta, F.; Spicer, A.J.; Amanuel, B.; et al. Droplet Digital PCR for Mutation Detection in Formalin-Fixed, Paraffin-Embedded Melanoma Tissues: A Comparison with Sanger Sequencing and Pyrosequencing. J. Mol. Diagn. 2018, 20, 240-252. [CrossRef] 
23. Hayashi, Y.; Fujita, K.; Matsuzaki, K.; Matsushita, M.; Kawamura, N.; Koh, Y.; Nakano, K.; Wang, C.; Ishizuya, Y.; Yamamoto, Y.; et al. Diagnostic potential of TERT promoter and FGFR3 mutations in urinary cell-free DNA in upper tract urothelial carcinoma. Cancer Sci. 2019, 110, 1771-1779. [CrossRef]

24. Descotes, F.; Kara, N.; Decaussin-Petrucci, M.; Piaton, E.; Geiguer, F.; Rodriguez-Lafrasse, C.; Terrier, J.E.; Lopez, J.; Ruffion, A. Non-invasive prediction of recurrence in bladder cancer by detecting somatic TERT promoter mutations in urine. Br. J. Cancer 2017, 117, 583-587. [CrossRef] [PubMed]

25. Akkari, Y.; Smith, T.; Westfall, J.; Lupo, S. Implementation of cancer next-generation sequencing testing in a community hospital. Cold Spring Harb. Mol. Case Stud. 2019, 5, a003707. [CrossRef]

26. Olmedillas-López, S.; García-Arranz, M.; García-Olmo, D. Current and Emerging Applications of Droplet Digital PCR in Oncology. Mol. Diagn. Ther. 2017, 21, 493-510. [CrossRef]

27. Perkins, G.; Lu, H.; Garlan, F.; Taly, V. Droplet-Based Digital PCR: Application in Cancer Research. Adv. Clin. Chem. 2017, 79, 43-91.

28. Corless, B.C.; Chang, G.A.; Cooper, S.; Syeda, M.M.; Shao, Y.; Osman, I.; Karlin-Neumann, G.; Polsky, D. Development of Novel Mutation-Specific Droplet Digital PCR Assays Detecting TERT Promoter Mutations in Tumor and Plasma Samples. J. Mol. Diagn. 2019, 21, 274-285. [CrossRef]

29. Sanmamed, M.F.; Fernández-Landázuri, S.; Rodríguez, C.; Zárate, R.; Lozano, M.D.; Zubiri, L.; Perez-Gracia, J.L.; Martín-Algarra, S.; González, A. Quantitative cell-free circulating BRAFV600E mutation analysis by use of droplet digital PCR in the follow-up of patients with melanoma being treated with BRAF inhibitors. Clin. Chem. 2015, 61, 297-304. [CrossRef]

30. Zvereva, M.; Pisarev, E.; Hosen, I.; Kisil, O.; Matskeplishvili, S.; Kubareva, E.; Kamalov, D.; Tivtikyan, A.; Manel, A.; Vian, E.; et al. Activating Telomerase TERT Promoter Mutations and Their Application for the Detection of Bladder Cancer. Int. J. Mol. Sci. 2020, 21, 6034. [CrossRef]

31. Burnham, P.; Dadhania, D.; Heyang, M.; Chen, F.; Westblade, L.F.; Suthanthiran, M.; Lee, J.R.; De Vlaminck, I. Urinary cell-free DNA is a versatile analyte for monitoring infections of the urinary tract. Nat. Commun. 2018, 9, 2412. [CrossRef] [PubMed]

32. McHugh, M.L. Interrater reliability: The kappa statistic. Biochem. Med. 2012, 22, 276-282. [CrossRef]

33. Meeks, J.J.; Al-Ahmadie, H.; Faltas, B.M.; Taylor, J.A.; Flaig, T.W.; DeGraff, D.J.; Christensen, E.; Woolbright, B.L.; McConkey, D.J.; Dyrskjøt, L. Genomic heterogeneity in bladder cancer: Challenges and possible solutions to improve outcomes. Nat. Rev. Urol. 2020, 17, 259-270. [CrossRef] [PubMed]

34. Warrick, J.I.; Sjödahl, G.; Kaag, M.; Raman, J.D.; Merrill, S.; Shuman, L.; Chen, G.; Walter, V.; DeGraff, D.J. Intratumoral Heterogeneity of Bladder Cancer by Molecular Subtypes and Histologic Variants. Eur. Urol. 2019, 75, 18-22. [CrossRef]

35. Pierson-Perry, J.F. EP17-A2: Evaluation of Detection Capability for Clinical Laboratory Measurement Procedures, 2nd ed.; Clinical and Laboratory Standards Institute (CLSI): Wayne, PA, USA, 2012; p. 80.

36. Zieliński, W. The Shortest Clopper-Pearson Confidence Interval for Binomial Probability. Commun. Stat.-Simul. Comput. 2009, 39, 188-193. [CrossRef]

37. Landis, J.R.; Koch, G.G. The Measurement of Observer Agreement for Categorical Data. Biometrics 1977, 33, 159-174. [CrossRef]

Publisher's Note: MDPI stays neutral with regard to jurisdictional claims in published maps and institutional affiliations.

(C) 2020 International Agency for Research on Cancer (IARC); Licensee MDPI, Basel, Switzerland. This is an open access article distributed under the terms of the Creative Commons Attribution IGO License (CC BY) (http://creativecommons.org/licenses/by/3. 0/igo/legalcode), which permits unrestricted use, distribution, and reproduction in any medium, provided the original work is properly cited. In any reproduction of this article there should not be any suggestion that IARC or this article endorse any specific organisation or products. The use of the IARC logo is not permitted. This notice should be preserved along with the article's original URL. 